\title{
ENCAPSULATION OF ALLOGENEIC MESENCHYMAL STEM CELLS IN ALGINATE EXTENDS LOCAL PRESENCE AND THERAPEUTIC FUNCTION
}

\author{
M.J.C. Leijs ${ }^{1,2}$, E. Villafuertes ${ }^{1,3}$, J.C. Haeck², W.J.L.M. Koevoet ${ }^{4}$, B. Fernandez-Gutierrez ${ }^{3}$, M.J. Hoogduijn ${ }^{4}$ \\ J.A.N. Verhaar ${ }^{1}$, M.R. Bernsen², G.M. van Buul ${ }^{1}$ and G.J.V.M. van Osch ${ }^{1,5, *}$ \\ ${ }^{1}$ Department of Orthopaedics, Erasmus MC, Rotterdam, The Netherlands \\ ${ }^{2}$ Department of Radiology, Erasmus MC, Rotterdam, The Netherlands \\ ${ }^{3}$ Rheumatology Service, Hospital Clinico San Carlos, Madrid, Spain \\ ${ }^{4}$ Department of Internal Medicine, Erasmus MC, Rotterdam, The Netherlands \\ ${ }^{5}$ Department of Otorhinolaryngology, Erasmus MC, Rotterdam, The Netherlands
}

\begin{abstract}
Bone marrow derived mesenchymal stem cells (MSCs) have immunomodulatory and trophic capacities. For therapeutic application in local chronic inflammatory diseases, MSCs, preferably of allogeneic origin, have to retain immunomodulatory properties. This might be achieved by encapsulation of MSCs in a biomaterial that protects them from the host immune system. Most studies investigating the properties of MSCs for therapeutic application use short term cultures of cells in monolayer. Since the physical environment of MSCs can influence their functionality, we evaluated the feasibility of preserving the immunomodulatory properties of MSCs encapsulated in a three-dimensional alginate construct.

After 5 weeks of implantation in immunocompetent rats, active allogeneic MSCs encapsulated in alginate were still detectable by Bio Luminescence Imaging and Magnetic Resonance Imaging of luciferase transduced and superparamagnetic iron oxide labelled MSCs. MSCs injected in saline were only detectable up to 1 week after injection. Moreover, the MSCs encapsulated in alginate responded to inflammatory stimuli similarly to MSCs in monolayer culture. In addition, MSC-alginate beads secreted immunomodulatory and trophic factors and inhibited T-cell proliferation after $30 \mathrm{~d}$ of in vitro culture. Our data indicate that allogeneic MSCs encapsulated in alginate persist locally and could act as an interactive immunomodulatory or trophic factor release system for several weeks, making this an interesting system to investigate for application in inflammatory disease conditions.
\end{abstract}

Keywords: Mesenchymal stem cells, alginate, construct, encapsulation, cell therapy, immunomodulation.

*Address for correspondence:

G.J.V.M. van Osch, $\mathrm{PhD}$

Department of Orthopaedics and Department of Otorhinolaryngology

Room Ee1655, Erasmus MC, Wytemaweg 80

3015 CN Rotterdam, The Netherlands

Telephone: +31 107043661

Email: g.vanosch@erasmusmc.nl

\section{Introduction}

Mesenchymal stem cells (MSCs) are multipotent cells that can be found in several tissues such as bone marrow, adipose tissue, synovium, deciduous teeth, umbilical cord blood and blood vessels (Awad et al., 2004; De Angelis et al., 1999; Lee et al., 2004; Sottile et al., 2002). As they are promising candidates for cell therapy, they are used as therapeutic agents in experimental models of tissue diseases such as osteoarthritis (OA), interstitial lung diseases, glomerulonephritis, graft versus host disease (GvHD) and myocardial infarction (Kunter et al., 2006; Le Blanc et al., 2004; Lee et al., 2006; Minguell and Erices, 2006; Ortiz et al., 2007; Rodriguez-Merchan, 2014). MSCs are a promising cell type for therapy, because they have the potential to differentiate into repair tissue and also have trophic and immunomodulatory capacities. While they have been shown to be capable of improving damaged tissue, their contribution does not seem to originate from long-term engraftment and differentiation (Toma et al., 2002; Zhang et al., 2015). This suggests that MSCs can also stimulate endogenous tissue repair, in addition to their ability to differentiate into cells of the mesoderm lineage. The immunomodulatory property of MSCs is very useful when inflammation is a major contributor to the pathophysiology such as OA (Daghestani et al., 2014), rheumatoid arthritis (Komatsu and Takayanagi, 2015) or GvHD (Le Blanc et al., 2004). Immune suppression by MSCs needs to be induced by pro-inflammatory cytokines such as interferon (IFN) $\gamma$, tumour necrosis factor (TNF) $\alpha$, interleukin (IL)-1 $\alpha$ or IL-1 $\beta$ (Groh et al., 2005; Le Blanc et al., 2003; Ren et al., 2008). In vitro, MSCs can inhibit B cell derived antibody production (Comoli et al., 2008), generation and function of antigen presenting cells (Nauta et al., 2006) or T lymphocyte proliferation and proinflammatory cytokine production (Di Nicola et al., 2002; Krampera et al., 2003). In vivo, MSCs were able to reduce tissue degradation and inflammation in OA (Daghestani et al., 2014), reduce immune activity in autoimmune enteropathy (Parekkadan et al., 2008), prolong heart and skin allograft survival (Bartholomew et al., 2002; Popp et al., 2008) and improve experimental colitis (Gonzalez-Rey et al., 2009).

The mechanisms responsible for MSCs immune modulation have been acknowledged to be based on paracrine activity. Although it is not precisely known which factors cause the effects, it was demonstrated that prostaglandin E2 (PGE2) production, indoleamine 
2,3-dioxygenase (IDO) activity, suppression of nitric oxide (NO) production and secretion of cytokines such as IL-6 (Jiang et al., 2005; Meisel et al., 2004; Nauta et al., 2006) can be (partly) responsible. In addition, growth factors such as transforming growth factor $\beta 1$ (TGF- $\beta 1)$ and vascular endothelial growth factor (VEGF) (Wang et al., 2008), secreted by MSCs, have been shown to influence tissue repair and immunological processes (Mallat and Tedgui, 2002).

Most studies have considered the immunomodulatory properties of MSCs in 2-dimensional (2D) monolayer culture (Dominici et al., 2006), as cell expansion is necessary to obtain the cell numbers required for therapeutic applications. MSCs in monolayer can differ considerably in morphology, cell adhesion, cell cycle and differentiation from those in 3-dimensional (3D) environments in vitro or in vivo (Barminko et al., 2011; Birgersdotter et al., 2005; Cukierman et al., 2002; Griffith and Swartz, 2006; Hansen et al., 1994; Yamada and Cukierman, 2007). Most of these studies performed short-term 3D experiments. However, for clinical applications, where MSCs therapy is aimed at modulating chronic inflammatory reactions, their immunomodulatory properties have to be guaranteed for at least several weeks in order to improve the pathology.

The use of alginate might be interesting to retain cells at the desired location. Alginate, a natural polysaccharide isolated from brown seaweed, is the most common used gel for cell encapsulation due to its biocompatibility and stability in vivo (de Vos et al., 2002; Shoichet and Rein, 1996; Wu et al., 2007; Murua et al., 2008). Moreover, alginate has the capacity to protect encapsulated cells against recognition by the immune system (Barminko et al., 2011; Herrero et al., 2007; Kang et al., 2014; Trouche et al., 2010; Zanotti et al., 2013), which will enable the use of allogeneic cells. This would greatly enhance the clinical translatability of MSCs-based therapies.

In this study using longitudinal imaging, we evaluated whether encapsulation in alginate would prolong the local presence of allogeneic MSCs in an immunocompetent rat and if the cells would maintain their immunomodulatory and trophic function for a prolonged period after encapsulation.

\section{Materials and Methods}

\section{In vivo evaluation of MSCs activity and localisation after encapsulation in alginate}

Isolation, encapsulation and culture of MSCs

Animal experiments were performed with prior approval of the ethics committee for laboratory animal use (protocol \# EMC116-12-07,5,1).

MSC-alginate mix was polymerised in $102 \mathrm{mM}$ $\mathrm{CaCl}_{2}$ and washed two times in saline. Constructs were subcutaneously implanted on the back of sixteen weeks old immunocompetent male Wistar rats (Harlan Netherlands BV, Horst, The Netherlands). Allogeneic bone marrow MSCs from F344 rats (purchased from Millipore, Billerica, MA, USA) and xenogeneic human bone marrow MSCs were used. Human bone marrow derived MSCs were isolated by means of heparinised femoral shaft marrow aspirate from patients undergoing a total hip arthroplasty (after written informed consent with approval of the Medical Ethical Committee of Erasmus MC, protocol \#MEC-2004-142). Bone marrow aspirates were plated in low glucose culture medium (DMEM, Dulbecco's Modified Eagle's Medium; Gibco, Carlsbad, CA, USA) with heat inactivated $15 \%$ foetal calf serum (FCS; selected batch Lonza, Verviers, Belgium), $50 \mu \mathrm{g} / \mathrm{mL}$ gentamycin (Invitrogen, Carlsbad, CA, USA), $1.5 \mu \mathrm{g} / \mathrm{mL}$ Fungizone (Invitrogen), 1 ng/mL FGF2 (Instruchemie B.V., Delfzijl, The Netherlands), $0.1 \mathrm{mM}$ vitamin C (Sigma, St. Louis, MO, USA) and after $24 \mathrm{~h}$ non-adherent cells were removed by washing with $2 \%$ FCS in PBS. Adherent cells were cultured and upon passaging seeded at a density of 2,300 $\mathrm{MSCs} / \mathrm{cm}^{2}$ and trypsinised (Invitrogen) at subconfluence. MSCs from the third to fourth passage were used for experiments.

Activity evaluation of long-term encapsulated allogeneic MSCs in vivo

To evaluate the retention of viable, encapsulated allogeneic MSCs in vivo, we performed bioluminescence imaging (BLI) of luciferase transduced F344 MSCs (Fluc-MSCs) as described before (Guenoun et al., 2013). 3D MSCalginate constructs with $4 \times 10^{6}$ Fluc-MSCs/mL filtersterilised $1.2 \%$ low viscosity alginate (Keltone LV, Kelco, Surrey, UK) were prepared. The MSC-alginate mix was polymerised in a sterilised, custom-designed mould consisting of two Durapore membranes $(5 \mu \mathrm{m}$ pore size; Millipore) at both sides of a $3 \mathrm{~mm}$ thick metal ring (Wong et al., 2001). The final cylindrical constructs of $8 \mathrm{~mm}$ diameter, containing a volume of approximately $151 \mu \mathrm{L}$ and an estimated cell number of $6 \times 10^{5} \mathrm{MSCs}$ were made with sterile dermal punches $(8 \mathrm{~mm}$; Spengler, Hannover, Germany). We compared subcutaneous implantation of six allogeneic MSC-alginate constructs in one rat with six subcutaneous injections of $6 \times 10^{5}$ allogeneic MSCs in physiological saline in another rat. The subcutaneous immunocompetent rat model is well accepted to study biocompatibility and tissue reactions. Moreover, it allows reliable longitudinal imaging of luminescence and iron oxide particles. Longitudinal cell viability was measured by luciferase activity of the transplanted and injected MSCs $30 \mathrm{~min}$ after intraperitoneal (i.p.) injection of $100 \mu \mathrm{g} /$ $\mathrm{kg}$ of D-luciferine (Promega Benelux B.V., Leiden, The Netherlands) using the Xenogen IVIS spectrum (Caliper LS, Hopkington, MA, USA) for an emission detection time of $10 \mathrm{~min}$. Sensitivity of our BLI was evaluated by BLI signal measurements of different amounts of FlucMSCs in vitro (data not shown). Minimum detection limit was 50,000 cells/well in monolayer in a 48-well plate. In vivo the optimal BLI signal over time was evaluated by repeated $10 \mathrm{~min}$ imaging after admission of D-luciferine up to $1 \mathrm{~h}$. Optimal bioluminescence signal detection with BLI was 30 min after admission of D-luciferine. BLI signal increased the first 30 min after D-luciferine admission; after $30 \mathrm{~min}$ the signal remained constant up to at least $1 \mathrm{~h}$. Best results were obtained with 10 min BLI measurements (integration time $600 \mathrm{~s}$; f/stop 1; binning medium; FOV C). In vivo scans were performed $1 \mathrm{~d}$ after implantation and weekly thereafter for a total of 5 weeks. Optical intensity 
is reported as arbitrary units. Data were analysed using the Living Image version 3.2 software (Caliper LS).

Localisation of long-term encapsulated allogeneic MSCs in vivo

To localise the allogeneic MSCs precisely, MSCs were labelled with superparamagnetic iron oxide (SPIO) $1 \mathrm{~d}$ prior to injection/implantation by using ferumoxides $100 \mu \mathrm{g} /$ mL medium (Endorem ${ }^{\mathrm{TM}}$, Guerbet S.A., Paris, France) complexed to protamine sulphate $5 \mu \mathrm{g} / \mathrm{mL}$ medium (LEO Pharma N.V., Wilrijk, Belgium) as described previously (van Buul et al., 2011). Magnetic resonance imaging (MRI) was performed directly after the cell implantation/injection to confirm the subcutaneous localisation of the SPIOFluc-MSCs. MR imaging was performed on a preclinical 7.0T MRI scanner (MR 901 Discovery, Agilent/GE Healthcare, Milwaukee, WI, USA) equipped with a $72 \mathrm{~mm}$ transmit/receive body coil. A fast spoiled gradient echo sequence was performed with the following settings: TE/ $\mathrm{TR}=1.1 / 7.3 \mathrm{~ms}, \mathrm{NEX}=4, \mathrm{FOV}=8 \times 6 \mathrm{~cm}^{2}$, acquisition matrix $=256 \times 192$, slice thickness $=1 \mathrm{~mm}$, bandwidth $=60 \mathrm{kHz}$, flip angle $=150^{\circ}$. Sagittal and coronal scans were performed to localise the hypo-intense SPIO deposits.

Histological evaluation of the implanted allogeneic MSCalginate constructs

5 weeks after implantation/injection, rats were euthanised directly after the last scans. The subcutaneous layer of the back of the rats, containing all transplanted/injected regions, was harvested, separated and scanned individually in the MRI to localise the correct injection/transplantation regions using the SPIO signal. Samples were fixed in $0.05 \mathrm{M}$ TRIS buffered saline with $10 \%$ formalin and $15 \mathrm{mM} \mathrm{CaCl}_{2}$ for $24 \mathrm{~h}$. All samples were embedded in paraffin. Sections of $6 \mu \mathrm{m}$ were sliced and deparaffinised before staining. Perl's iron staining (Klinipath BVBA, Duiven, The Netherlands) was performed, according to the manufacturer's protocol, to locate the SPIO-labelled MSCs. Perl's iron staining stained iron particles blue. CD68 staining was performed on the same sections to identify macrophages. Antigen retrieval for CD68 was performed through incubation in citrate buffer $(10 \mathrm{mM}$ citric acid, $0.05 \%$ Tween $20, \mathrm{pH} 6.0$ ) for $20 \mathrm{~min}$ at $90-95{ }^{\circ} \mathrm{C}$. Sections were incubated for $1 \mathrm{~h}$ with primary antibodies for CD68 (\#BM4000; OriGene Europe-Acris Antibodies, Herford, Germany) diluted to a concentration of $5 \mu \mathrm{g} / \mathrm{mL}$ in PBS/1 \% BSA (\#A7284; Sigma) after blocking of nonspecific binding sites with $10 \%$ goat serum (\#0060-01; Southern Biotech, Birmingham, AL, USA) in PBS/1 \% BSA. A secondary biotinylated antibody goat-anti-mouse 1:50 (HK-325-UM; Biogenex, Fremont, CA, USA) was used, followed by incubation with the third antibody streptavidin-AP 1:50 (HK-321-UK; Biogenex). Staining was then visualised using an alkaline-phosphate substrate followed by counter staining with haematoxylin. CD68 positive cells stained pink.

Evaluation of implanted xenogeneic MSC-alginate constructs

To evaluate reproducibility and to improve clinical translatability, we encapsulated human bone marrow derived MSCs in alginate. $4 \times 10^{6}$ MSCs were mixed in $1 \mathrm{~mL}$ filter-sterilised $1.2 \%$ low viscosity alginate and constructs were created by dripping the MSC-alginate mixture through a 23 -gauge needle in a $102 \mathrm{mM} \mathrm{CaCl}_{2}$ solution. Five constructs were subcutaneously implanted in two different rats for 5 weeks. Additionally, five alginate constructs without MSCs were subcutaneously implanted in two different rats to evaluate the effect of the alginate on the host immune system. 5 weeks after implantation, rats were euthanised and transplanted regions were harvested. Localisation of the constructs, human bone marrow MSCs and host immune reaction were evaluated with histological analysis by haematoxylin and eosin (HE) and CD68 staining.

\section{In vitro evaluation of MSCs function and survival after encapsulation in alginate \\ Stimulation of immunomodulatory properties}

Encapsulated human MSCs, isolated as described above, were cultured in DMEM low glucose medium with $2 \%$ FCS, $50 \mu \mathrm{g} / \mathrm{mL}$ gentamycin and $1.5 \mu \mathrm{g} / \mathrm{mL}$ Fungizone for $48 \mathrm{~h}$. To activate the immunomodulatory properties, MSC-alginate constructs were incubated $24 \mathrm{~h}$ in DMEM low glucose medium with $1 \%$ ITS (BD Bioscience, Bedford, MA, USA), $50 \mu \mathrm{g} / \mathrm{mL}$ gentamycin and $1.5 \mu \mathrm{g} /$ $\mathrm{mL}$ Fungizone supplemented with IFN $\gamma$ and TNF $\alpha$ (50 ng/ $\mathrm{mL}$ each; PeproTech, London, UK), designated as cytokine medium. As control, MSCs were cultured in monolayer until sub confluency and then incubated with control or cytokine medium for $24 \mathrm{~h}$.

To evaluate long-term function, MSC-alginate constructs were pre-cultured for $30 \mathrm{~d}$ and subsequently stimulated with cytokine medium. Constructs were harvested directly after the $24 \mathrm{~h}$ stimulation for gene expression analyses and medium was harvested and stored at $-80^{\circ} \mathrm{C}$ for analyses of secreted factors.

\section{Gene expression analyses}

Alginate was dissolved in $55 \mathrm{~m} M$ sodium citric acid (Sigma) and spun down for $8 \mathrm{~min}$ at $175 \times g$ at $4{ }^{\circ} \mathrm{C}$. Cell pellets were resuspended in $1 \mathrm{~mL}$ RNABee (Tel-test, Firendswood, TX, USA) for RNA isolation. The monolayer MSCs cultures in 6-well plates were resuspended in $1 \mathrm{~mL}$ RNABee. After addition of $0.2 \mathrm{~mL}$ chloroform, samples were spun down for $15 \mathrm{~min}$ at $12,000 \times g$. Total RNA was isolated from the supernatant using the Qiagen RNA Micro Kit according to the manufacturer's instructions (Qiagen, Hilden, Germany) and nucleic acid content was determined spectrophotometrically (NanoDrop ND1000, Isogen Life Science, IJsselstein, The Netherlands). cDNA was generated according to manufacturer's instructions using RevertAid ${ }^{\mathrm{TM}}$ First Strand cDNA Synthesis Kit (MBI Fermentas, St. Leon-Rot, Germany). Gene expression analysis was performed using ABI7000 cycle. Cycle threshold $(\mathrm{Ct})$ values were corrected by the best housekeeper index (BKI), which was calculated by the average of glyceraldehyde-3-phosphate dehydrogenase (GAPDH; Fw: ATGGGGAAGGTGAAGGTCG; Rv: TAAAAGCAGCCCTGGTGACC; Probe:FamCGCCCAATACGACCAAATCCGTTGAC), ubiquitin C (UBC; Fw: ATTTGGGTCGCGGTTCTTG; 
Rv: T GC C T T GA CAT T C T CGATGG T) and hypoxanthine phosphoribosyltransferase (HPRT; Fw: TATGGACAGGACTGAACGTCTTG; Rv: CACACAGAGGGCTACAATGTG; Probe: FamAGATGTGATGAAGGAGATGGGAGGCCA).

RT-PCR primer nucleotide sequences used for IL-6, tissue inhibitor of metalloproteinases (TIMP-1), TIMP-2, IDO, TGF- $\beta 1$ and VEGF were described previously (Yuan et al., 2014). Relative expression levels were calculated using the $2^{-\Delta \mathrm{Ct}}$ method (Schmittgen and Livak, 2008).

\section{Enzyme-Linked Immuno Sorbent Assay}

TIMP-2 and IL-6 protein levels were measured in stimulated and non-stimulated MSC-conditioned media from three donors by means of ELISA assay according to the manufacturer's protocol (R\&D systems, Abingdon, UK). All factors were corrected for the amounts present in standard MSC culture medium. To determine the amount of IDO enzymatic activity in MSC media, the level of its metabolite L-kynurenine was measured spectrophotometrically as described previously (Kang et al., 2008).

\section{Immunomodulation by MSC-alginate constructs}

MSC-alginate constructs were co-cultured with activated lymphocytes to study their immunosuppressive capacity. Therefore, peripheral blood mononuclear cells (PBMCs) were isolated from buffy coats of healthy blood donors (Sanquin, Rotterdam, The Netherlands) using FicollPaque $^{\text {TM }}$ PLUS (density $1.077 \mathrm{~g} / \mathrm{mL}$; GE Healthcare, Uppsala, Sweden) separation. Cells were frozen at $-150^{\circ} \mathrm{C}$ until further use in RPMI-1640 medium containing $1 \%$ GlutaMAX $^{\text {TM}}-$ I (Life Technologies, Waltham, MA, USA) supplemented with $1 \% \mathrm{P} / \mathrm{S}$ (Penicillin 10,000 UI/mL, Streptomycin 10,000 UI/mL; Lonza), $10 \%$ human serum (Sanquin) and $10 \%$ dimethylsulphoxide (DMSO, Merck, Hohenbrunn, Germany).

MSC-alginate constructs containing $4 \times 10^{6}$ cells $/ \mathrm{mL}$ resulted in approximately $3 \times 10^{4}$ MSCs per construct. $2 \mathrm{~d}$ and $30 \mathrm{~d}$ after encapsulation, MSCs were either stimulated with cytokine medium or cultured in control medium ( $150 \mu \mathrm{L} / \mathrm{bead}$ ) for $24 \mathrm{~h}$. After $24 \mathrm{~h}$ constructs were washed two times with PBS and transferred per four, two, and one bead in a 48-wells plate in triplicate.

PBMCs were thawed and washed extensively with PBS to remove FCS and brought to a concentration of $1 \times 10^{7}$ cells $/ \mathrm{mL}$ in PBS and labelled with $1 \mu \mathrm{M}$ carboxyfluorescein succinimidyl ester (CFSE) by quickly mixing followed by 7 min incubation at $37^{\circ} \mathrm{C}$. Cells were resuspended in RPMI medium with $1 \% \mathrm{P} / \mathrm{S}$ and $10 \% \mathrm{FCS}$ and, to stimulate T-cell activation, antibodies against CD3 and CD28 $(1 \mu \mathrm{L}$ per $1 \times 10^{6}$ cells in $1 \mathrm{~mL}$ ) were added to the suspension with a cross-linking antibody $\left(2 \mu \mathrm{L}\right.$ per $1 \times 10^{6}$ cells in $\left.1 \mathrm{~mL}\right)$ (all from BD Biosciences, Bedford, MA, USA). $3 \times 10^{5}$ stimulated CFSE-PBMCs in $600 \mu \mathrm{L}$ were added to the alginate beads in a 48 -well plate. As positive and negative $T$ lymphocyte proliferation control, $3 \times 10^{5} / 600 \mu \mathrm{L}$ stimulated and non-stimulated CFSE-PBMCs were cultured in triplicate. Stimulated CFSE-PBMCs with 4 empty alginate beads (not containing MSCs) were used as baseline control.
As a positive control for the proliferation inhibitory effect, MSCs in monolayer were plated at a density of $1.2 \times 10^{5}$ MSCs/well in a 48-well plate. After $24 \mathrm{~h}$ of attachment MSCs were stimulated or non-stimulated with cytokine medium for $24 \mathrm{~h}$. After stimulation, cells were washed two times with PBS, and $3 \times 10^{5}$ stimulated CFSE-PBMCs suspended in $600 \mu \mathrm{L}$ were added. After $5 \mathrm{~d}$ of co-culture, PBMCs were retrieved, labelled for $30 \mathrm{~min}$ with $\mathrm{CD} 8 / \mathrm{CD} 4$ (BD Biosciences). Cells were analysed by fluorescenceactivated cell sorting (FACS) on a FACS Canto II flow cytometer (BD Biosciences). After initial broad selection of lymphocytes based on forward and side scatter to exclude dead cells and debris, we selected the single CD4+ and single CD8+ cells. Proliferation of these cells was analysed by decrease of CFSE label.

\section{Characterisation of the encapsulated MSCs}

To evaluate if the MSCs maintained their multilineage differentiation capacity after 2 and $30 \mathrm{~d}$ of encapsulation in alginate, the alginate structure was disrupted using sodium citrate/ethylene diamine tetra acetate (EDTA, Sigma) to release the cells and osteogenic and adipogenic differentiation was performed for $21 \mathrm{~d}$. For osteogenic differentiation, MSCs were plated at a density of $3 \times 10^{3}$ cells $/ \mathrm{cm}^{2}$ and cultured in high glucose DMEM (Gibco) containing $10 \%$ FCS, $10 \mathrm{mM} \beta$-glycerophosphate (Sigma), $0.1 \mu \mathrm{M}$ dexamethasone (Sigma) and $0.5 \mathrm{mM}$ L-ascorbic acid 2 phosphate (Sigma). For adipogenic differentiation, MSCs were plated at a density of $2 \times 10^{4}$ cells $/ \mathrm{cm}^{2}$ and cultured in high glucose DMEM containing $10 \%$ FCS, $1 \mu \mathrm{M}$ dexamethasone, $0.2 \mathrm{mM}$ indo-methacin (Sigma), $0.01 \mathrm{mg} / \mathrm{mL}$ insulin (Sigma) and $0.5 \mathrm{mM} \mathrm{3-isobutyl-1-}$ methyl-xanthine (Sigma). All media contained $50 \mu \mathrm{g} /$ $\mathrm{mL}$ gentamycin and $1.5 \mu \mathrm{g} / \mathrm{mL}$ Fungizone. Histological evaluation was performed with Von Kossa staining (Sigma) for osteogenic differentiation and Oil Red O (Sigma) for adipose differentiation.

\section{DNA Content}

To determinate cell survival after one month of encapsulation in alginate we measured DNA content weekly $(t=0,7,14$, 21 and $30 \mathrm{~d}, n=4$ donors). Beads were digested overnight at $56{ }^{\circ} \mathrm{C}$ in papain digestion buffer $(250 \mu \mathrm{g} / \mathrm{mL}$ papain in $50 \mathrm{mM}$ EDTA and $5 \mathrm{mM}$ 1-cysteine hydrochloride; all from Sigma). The amount of DNA in each papain-digested sample was analysed in the Wallac 1420 victor2 (PerkinElmer, Wellesley, MA, USA) using an extinction filter of $340 \mathrm{~nm}$ and an emission filter of $590 \mathrm{~nm}$ by means of an ethidium bromide assay (Sigma) with calf thymus DNA as a standard (Royce and Lowther, 1979).

\section{Statistics}

Statistical analysis of the in vivo BLI data was performed by Mann-Whitney U tests. The in vitro T-cell proliferation data were analysed in SPSS 21.0 (IBM) by ANOVA with Dunnett's correction using empty beads as control group. Analyses of the in vitro data were performed by two way ANOVA test using GraphPad Prism 5.00. $p<0.05$ was considered statistically significant. 


\section{Results}

Alginate encapsulated allogeneic MSCs were retained in immunocompetent rats for at least 5 weeks.

To evaluate long-term cell activity, we subcutaneously implanted allogeneic rat SPIO-Fluc-MSCs encapsulated in alginate and compared this to subcutaneously injected SPIO-Fluc-MSCs suspended in saline. MSCs encapsulated and MSCs injected were well tolerated without any macroscopic sign of inflammation in the immunocompetent animals. Clear BLI signal of SPIO-Fluc-MSCs was observed directly after both implantation of alginate-cell constructs and injection of cells suspended in saline (Fig. 1 A,B). From 2 weeks onward, injected cells could no longer be detected, whereas BLI signal of the encapsulated SPIO-Fluc-MSCs in alginate constructs remained clearly visible till the end of the study, 5 weeks after implantation (Fig. 1 C-E)

MRI images confirmed the subcutaneous location of the six SPIO-Fluc-MSC-alginate constructs and the six subcutaneously SPIO-Fluc-MSCs injected regions directly after implantation or injection (Fig. 2A,B). For all time points, hypo-intense signal from SPIO remained visible on MR images. The SPIO signal voids created by encapsulated F344 SPIO-Fluc-MSCs became less hypo-intense over time but remained comparable in size. The injected cellsuspension on the other hand generated smaller signal voids over time, although intensity remained approximately the same (Fig. 2C,D). Histology of the subcutaneous transplantation regions was performed at the end of the study to confirm presence of implanted cells. Perl's iron staining confirmed the presence of SPIO containing cells in subcutaneous regions of encapsulated and injected MSCs. In the injected MSCs condition, cells were positive for CD68 and Perl's iron staining, indicating death of the MSCs and uptake of the released iron by macrophages (Fig. 3A), corresponding to the deceased BLI signal of the injected SPIO-Fluc-MSCs. Encapsulated SPIO-FlucMSCs had a viable appearance, were found isolated in the alginate and positive for Perl's iron and negative for CD68 (Fig. 3B).

To improve clinical translatability of the allogeneic rat MSCs results in vivo, we implanted encapsulated human bone marrow MSCs subcutaneously in rats for 5 weeks. Transplantation of these xenogeneic MSCs was well tolerated without any macroscopic sign of inflammation in the immunocompetent rats. Histology confirmed the presence of alginate encapsulated MSCs with a viable aspect at HE staining (Fig. 3C), without signs of macrophage infiltration (Fig. 3D,E). Alginate constructs without MSCs did not show ingrowth of host cells or macrophage infiltration (Fig. 3F,G). By encapsulating allogeneic and xenogeneic MSCs in alginate it was possible to retain MSCs in one location for at least 5 weeks in an in vivo setting.

\section{MSC-alginate constructs retain long-term immunomodulatory capacity in vitro}

Expression of immunomodulatory and trophic genes in encapsulated MSCs

We evaluated the effect of alginate-encapsulation on several properties of human bone marrow derived MSCs. To study the immunomodulatory and trophic capabilities after encapsulation, MSCs were stimulated for $24 \mathrm{~h}$ with IFN $\gamma / \mathrm{TNF} \alpha$ after $2 \mathrm{~d}$ of culture in alginate. Encapsulated MSCs were compared to monolayer cultured cells.

MSCs encapsulated in alginate constructs responded to IFN $\gamma / \mathrm{TNF} \alpha$ very similarly to MSCs cultured in monolayer (Fig. 4). Gene expression of IL-6 and IDO $(p<0.05)$ was up-regulated in response to IFN $\gamma / \mathrm{TNF} \alpha$ in both monolayer and alginate culture. TGF- $\beta 1$ was down-regulated in all conditions but only reached significance in alginate cultures $(p<0.05)$, whereas VEGF was only significantly down-regulated in monolayer cultures $(p<0.05)$. To check whether MSCs in alginate maintained their immunomodulatory and trophic response capacity for a longer period, we performed $24 \mathrm{~h}$ stimulation with control and cytokine medium on encapsulated MSCs, which had been in culture for $30 \mathrm{~d}$. MSCs retained a response to IFN $\gamma / \mathrm{TNF} \alpha$ similar to the $2 \mathrm{~d}$ cultured alginate beads with up-regulated IL- 6 and IDO expression $(p<0.05)$ and down-regulated TGF- $\beta 1$, TIMP-1 and TIMP-2 expression $(p<0.05)$ while VEGF was not significantly altered (Fig. $4)$.

Secretion of immunomodulatory factors by MSC-alginate constructs

MSCs cultured in monolayer secreted IL-6 and TIMP-2, and expressed IDO activity. MSCs encapsulated in alginate for 2 and $30 \mathrm{~d}$ secreted IL-6 and TIMP-2, and expressed IDO activity as well (Table 1). IDO activity and IL-6 secretion were increased by IFN $\gamma / \mathrm{TNF} \alpha$ at all time-points,

Table 1. Immunomodulatory factors in conditioned medium of MSCs

\begin{tabular}{|c|c|c|c|c|c|c|}
\hline & \multicolumn{2}{|c|}{ 2 d monolayer } & 2 d encapsulation in alginate & \multicolumn{2}{c|}{ 30 d encapsulation in alginate } \\
\hline & Control & Cytokine & Control & Cytokine & Control & Cytokine \\
\hline IL-6 pg/mL & $5495 \pm 553$ & $53594 \pm 3335^{\text {a }}$ & $1650 \pm 1271$ & $36044 \pm 23304$ & UD & $4148 \pm 2439$ \\
\hline TIMP2 $\mathbf{~ p g / m L ~}$ & $26181 \pm 5099$ & $27750 \pm 3917$ & $15541 \pm 8027$ & $15291 \pm 7669$ & $9483 \pm 6913$ & $8635 \pm 5518$ \\
\hline Kynurenine $\mathbf{~ n g / m L ~}$ & $440 \pm 158$ & $13069 \pm 1012^{\mathrm{b}}$ & $690 \pm 631$ & $11531 \pm 102^{\mathrm{a}}$ & $1430 \pm 1430$ & $7661 \pm 1548 \mathrm{a}$ \\
\hline
\end{tabular}

Measurement of immunomodulatory factors in conditioned medium of MSCs with or without stimulation by inflammatory cytokines IFN $\gamma$ and TNF $\alpha$ for $24 \mathrm{~h}$. MSCs were cultured in monolayer for $2 \mathrm{~d}$ (control condition) or encapsulated in alginate and cultured for $2 \mathrm{~d}$ and $30 \mathrm{~d}$ before $24 \mathrm{~h}$ of stimulation. IL- 6 (pg/mL) and TIMP-2 $(\mathrm{pg} / \mathrm{mL})$ secretion were measured in the conditioned medium by ELISA. IDO enzymatic activity was measured spectrophotometrically by means of L-kynurenine level $(\mathrm{ng} / \mathrm{mL})$ in the conditioned medium. Mean $\pm \mathrm{SD}$ is shown. $n=3$ donors with triplicate samples per donor. ${ }^{\mathrm{a}} p<0.05,{ }^{\mathrm{b}} p<0.01$ comparing control and cytokine medium. Under detection limit, UD. 

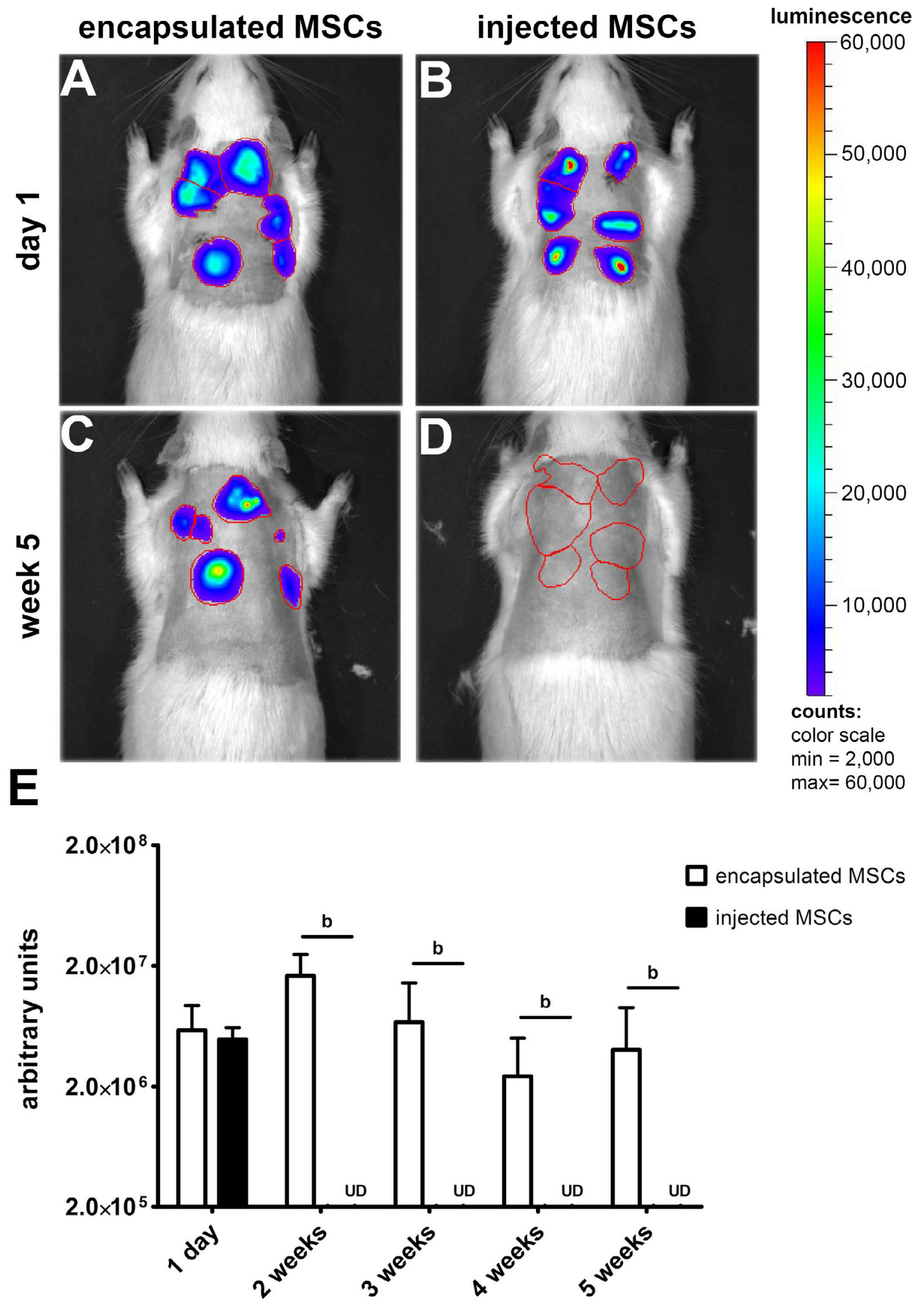

Fig. 1. Long-term cell activity of allogeneic rat SPIO-Fluc-MSCs in vivo in an immunocompetent rat. BLI signal of encapsulated allogeneic rat MSCs and injected allogeneic rat MSCs subcutaneously in immunocompetent rats $(\mathbf{A}, \mathbf{B})$ $1 \mathrm{~d}$ and (C,D) 5 weeks after implantation/injection. (E) Quantification of BLI signal generated by viable rat SPIOFluc-MSCs up to 5 weeks depicted as arbitrary units: white bars represent encapsulated allogeneic rat MSCs, black bars represent injected allogeneic rat MSCs. The 1 week time point was excluded due to a technical failure during luciferin injection. $6 \times 10^{5}$ rat MSCs were implanted/injected per location with a total of 6 locations per rat. Mean $\pm \mathrm{SD}$ is shown, ${ }^{\mathrm{b}} p<0.01$. UD $=$ undetectable. 


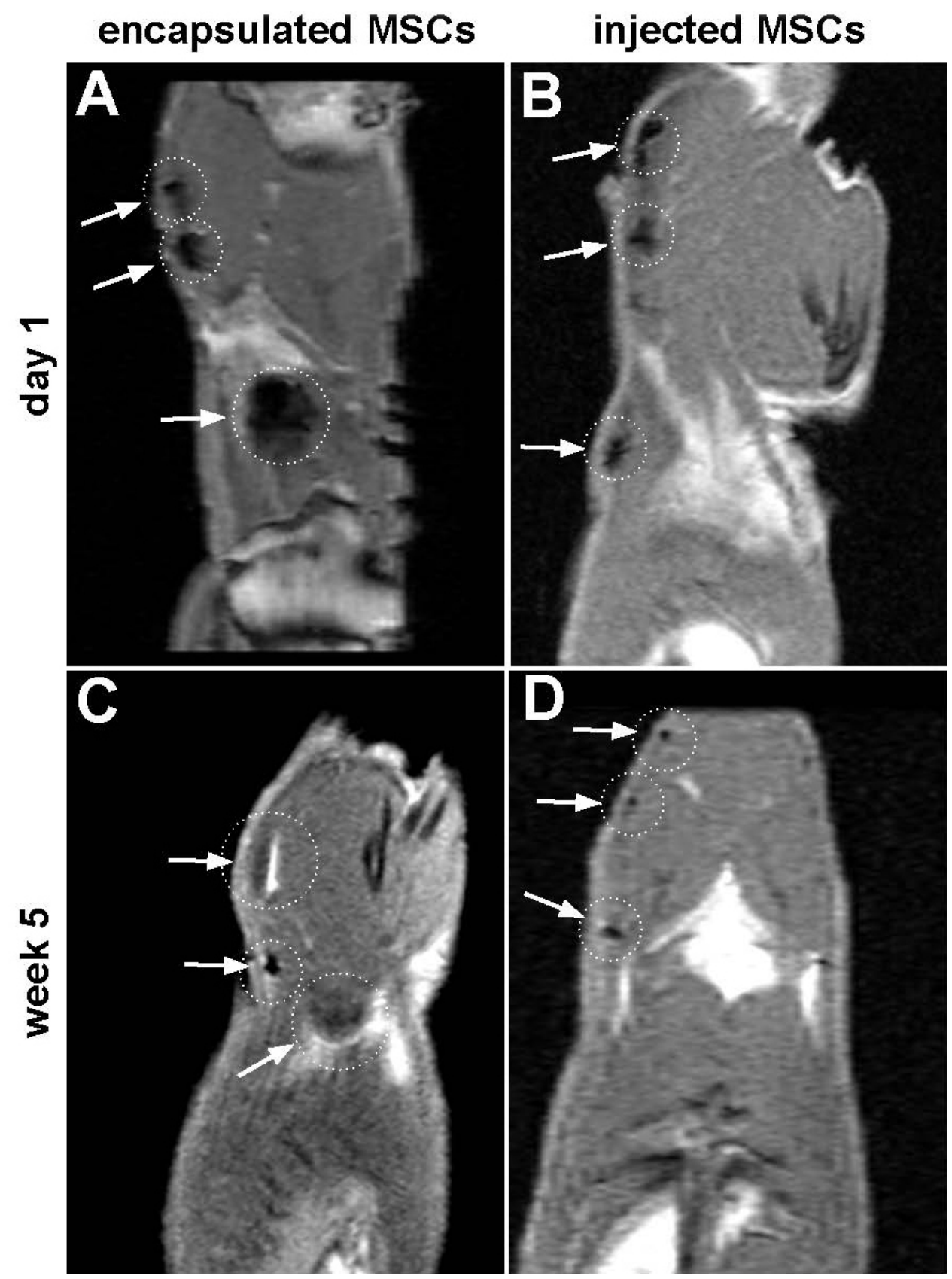

Fig. 2. Long-term localisation of allogeneic rat SPIO-Fluc-MSCs applied subcutaneously in immunocompetent rats by MRI. Oblique views of MR images confirmed the subcutaneous location of the encapsulated allogeneic rat MSCs and injected allogeneic rat MSCs (A,B) $1 \mathrm{~d}$ after implantation/injection and $(\mathbf{C}, \mathbf{D}) 5$ weeks after implantation/injection. Due to the different subcutaneous implantation/injection locations, only three pockets can be displayed in a plane image.

in accordance with gene expression analysis (albeit IL-6 did not reach statistical significance in alginate cultures due to high donor variation in absolute secretion levels. Nevertheless, in all donors IL-6 secretion increased after IFN $\gamma / \mathrm{TNF} \alpha$ treatment). The absolute IDO activity and IL-6 secretion diminished between $2 \mathrm{~d}$ and $30 \mathrm{~d}$ pre-culture. TIMP-2 secretion was not affected by cytokine treatment.

Immunomodulatory effect of MSC-alginate constructs Immunomodulation by MSC-alginate constructs was evaluated by the effect on $\mathrm{T}$ lymphocyte proliferation. MSC-alginate constructs that were cultured for $2 \mathrm{~d}$ significantly inhibited proliferation of stimulated CD4+ and CD8+ T lymphocytes in a dose-dependent manner (Fig.
5). Four MSC-alginate constructs (approximately $3 \times 10^{4}$ cells/bead) $2 \mathrm{~d}$ after encapsulation had similar inhibitory effect on stimulated $\mathrm{T}$ lymphocytes (68\% inhibition for CD4+ cells; $52 \%$ for CD8+ cells compared to the control with 4 empty constructs; $p<0.05$ ) as the MSCs monolayer control (approximately $1.2 \times 10^{5}$ cells per well). This effect diminished after $30 \mathrm{~d}$ of encapsulation, albeit all conditions still inhibited CD4+ T lymphocyte proliferation and four MSC-alginate constructs still significantly inhibit CD8+-T lymphocyte proliferation (Fig 5; inhibition CD4+ proliferation $30 \%$ and CD8+ proliferation $12 \%$ with 4 constructs). Pre-stimulation of MSC-alginate constructs with IFN $\gamma / \mathrm{TNF} \alpha$ for $24 \mathrm{~h}$ did not influence the inhibitory effects on $\mathrm{T}$ lymphocyte proliferation (data not shown). 


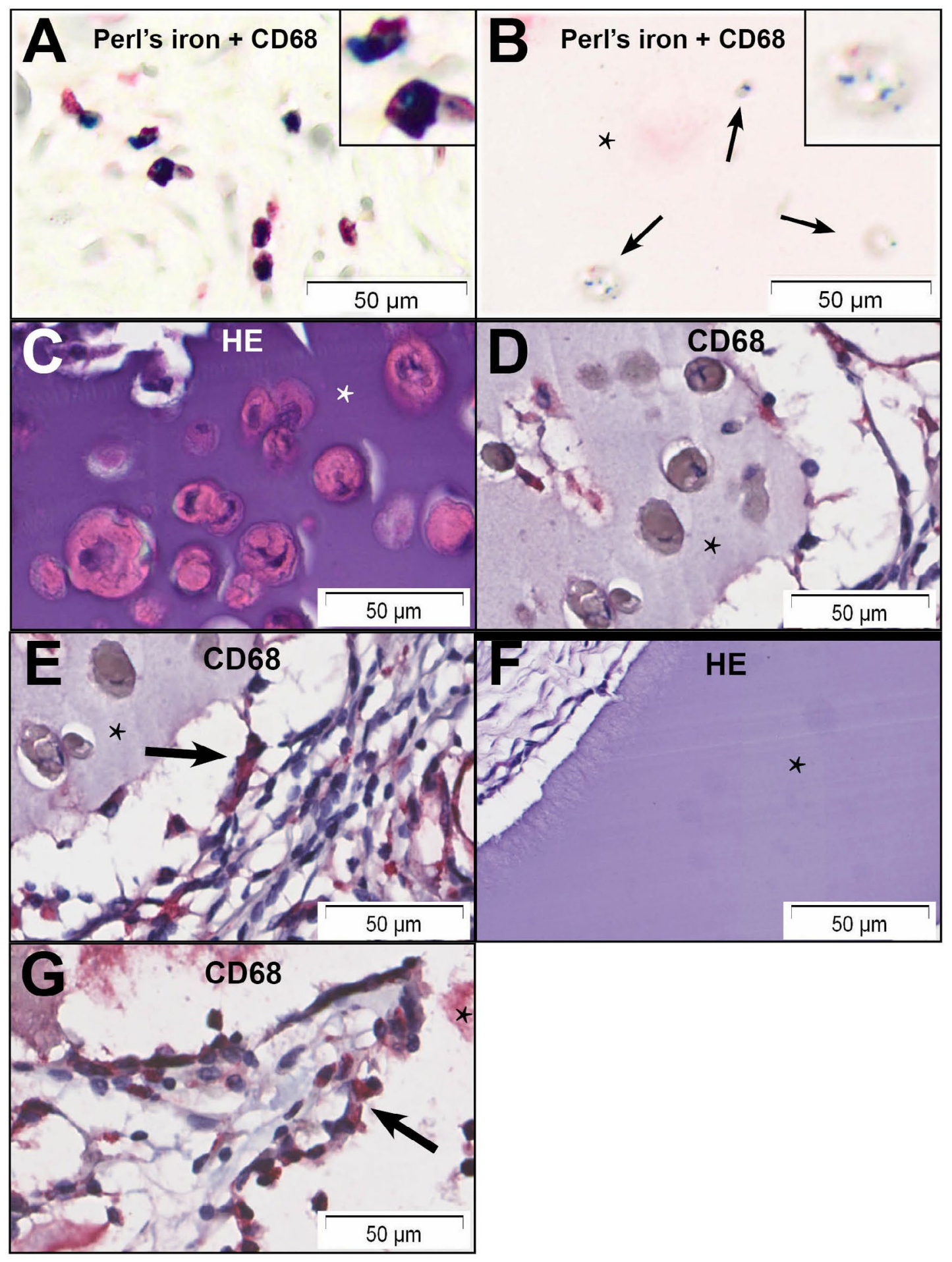

Fig. 3. Histology of the subcutaneous implanted/injected allogeneic and xenogeneic MSCs in immunocompetent rats, 5 weeks after implantation/injection. (A,B) Implanted/injected allogeneic rat SPIO-Fluc-MSCs were stained with Perl's iron staining (blue), which stains SPIO. CD68 staining (pink) was used to stain macrophages. (A) Injected cells were positive for Perl's iron and CD68 staining suggesting macrophage phagocytosis of SPIO and MSC death, while (B) the Perl's iron and CD68 staining in combination confirmed SPIO labelled MSCs (arrows) encapsulated in alginate without CD68 staining. (C) Implanted encapsulated xenogeneic human bone marrow derived MSCs were stained with haematoxylin and eosin (HE) staining, which shows isolated MSCs in the alginate with a viable appearance. (D) CD68 staining was used to identify macrophages and the encapsulated MSCs were negative for CD68. (E) Some macrophages were identified in the host tissue around the construct (arrow) without evident macrophage infiltrations. (F) Alginate constructs without MSCs were implanted as a control. HE staining showed no cell infiltration in the constructs. (G) CD68 staining showed some macrophages in the host tissue surrounding the alginate construct without MSCs (arrow), but no evident macrophage infiltrations were found. Haematoxylin and eosin staining (HE), *asterisk indicates alginate in $\mathrm{B}, \mathrm{C}, \mathrm{D}$ and $\mathrm{F}$ and indicates the location where the alginate was located before processing the sample for CD68 staining in $\mathrm{E}$ and $\mathrm{G}$. 

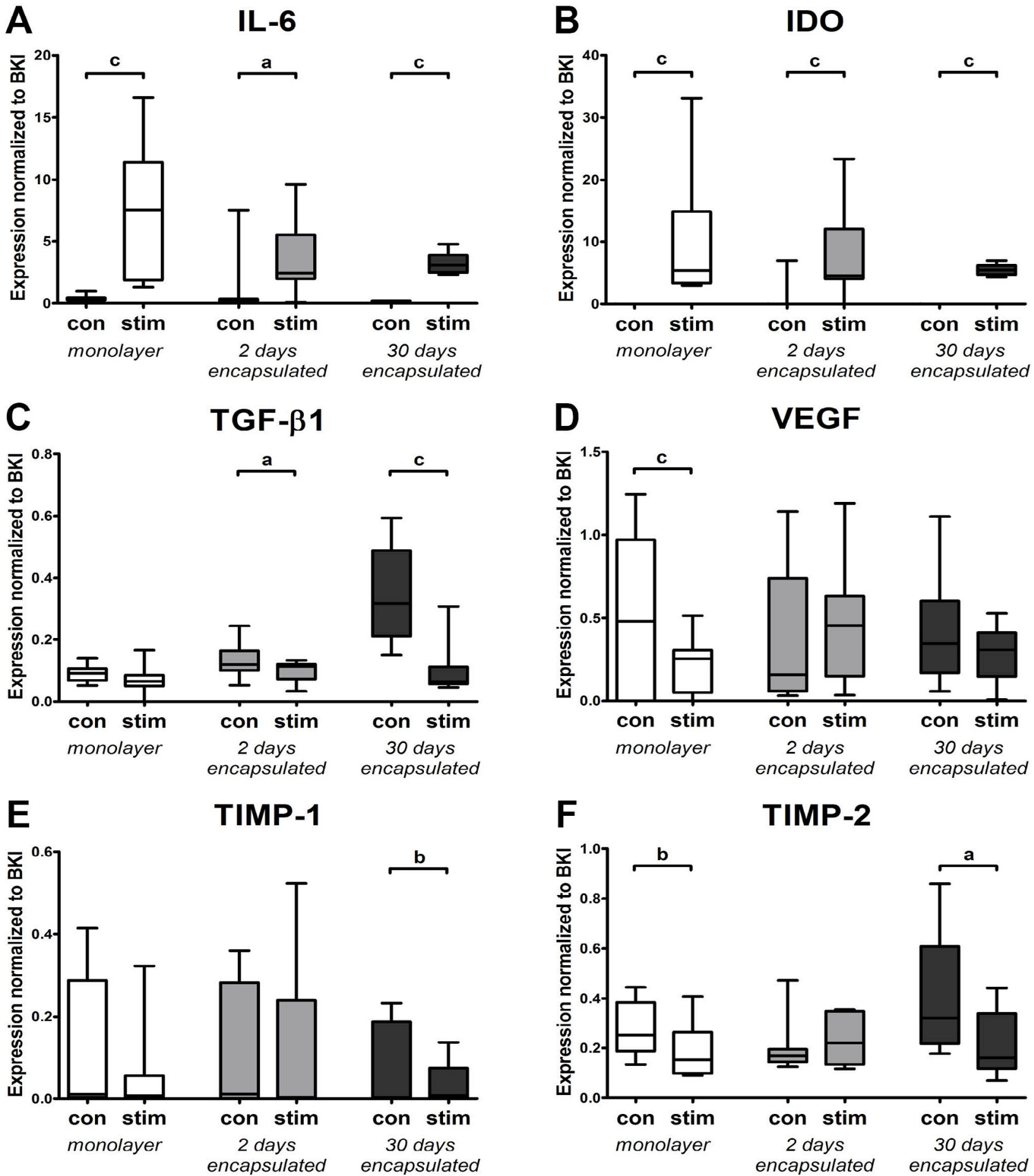

Fig. 4. Gene expression of immunomodulatory and trophic genes by MSCs with or without stimulation by inflammatory cytokines IFN $\gamma / \mathrm{TNF} \alpha$ for $24 \mathrm{~h}$. MSCs were cultured in monolayer for $2 \mathrm{~d}$ (control condition) or encapsulated in alginate and cultured for $2 \mathrm{~d}$ and $30 \mathrm{~d}$ before $24 \mathrm{~h}$ of stimulation. Box and whisker plot 2.5-97.5 percentile is shown. $n=4$ donors with duplicate or triplicate samples per donor. BKI (best house keeper index) as average of glyceraldehyde-3-phosphate dehydrogenase (GAPDH), ubiquitin C (UBC) and hypoxanthine phosphoribosyltransferase (HPRT); Interleukin 6, IL-6; Indoleamine 2, 3-dioxygenase, IDO; Transforming growth factor $\beta 1$, TGF- $\beta 1$; Vascular endothelial growth factor, VEGF; Tissue inhibitor of metalloproteinases 1, TIMP-1; Tissue inhibitor of metalloproteinases 2, TIMP-2; non-stimulated cells with IFN $\gamma / \mathrm{TNF} \alpha$ as control, con, stimulated cells with IFN $\gamma / \mathrm{TNF} \alpha$ for $24 \mathrm{~h}$, stim. ${ }^{\mathrm{a}} p<0.05,{ }^{\mathrm{b}} p<0.01,{ }^{\mathrm{c}} p<0.001$. 
A

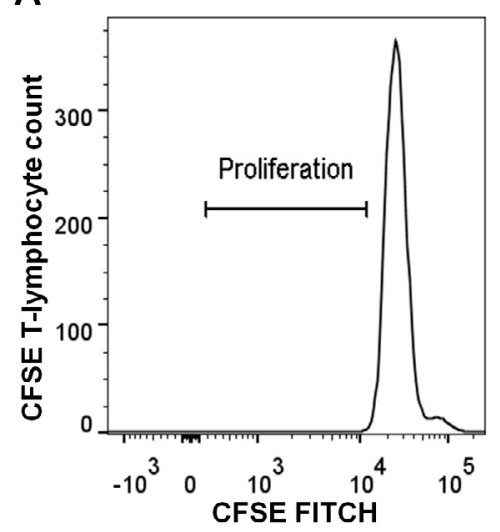

E

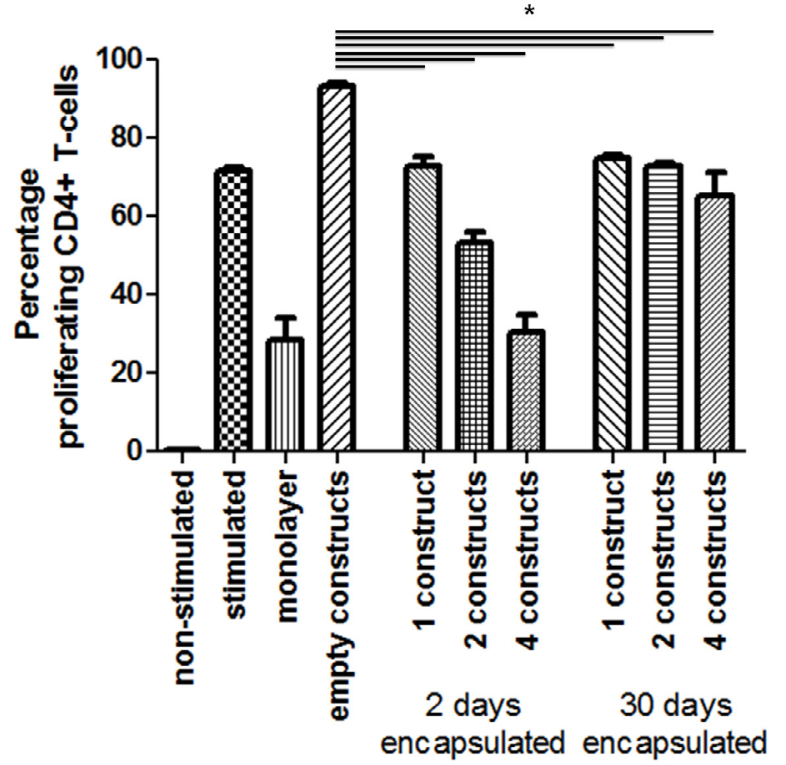

B

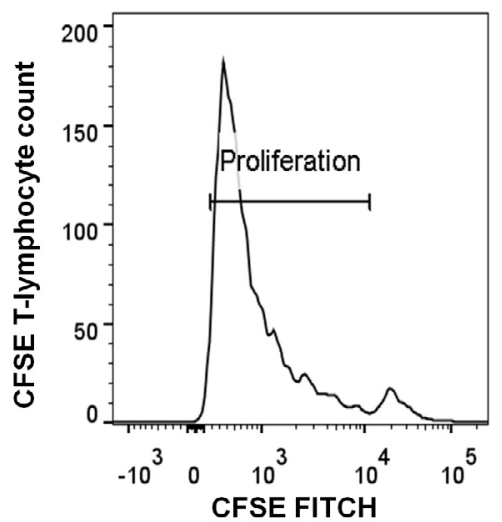

C

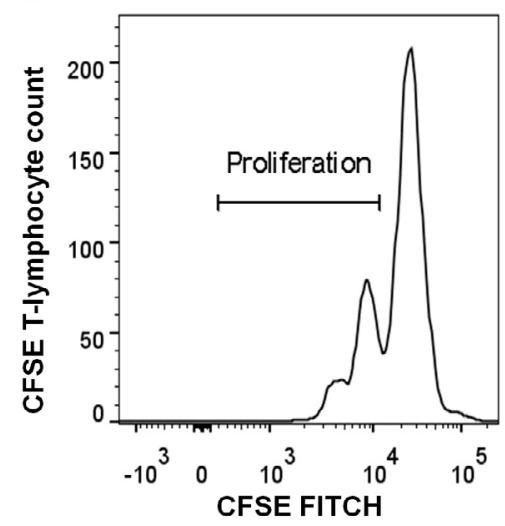

$\mathbf{F}$

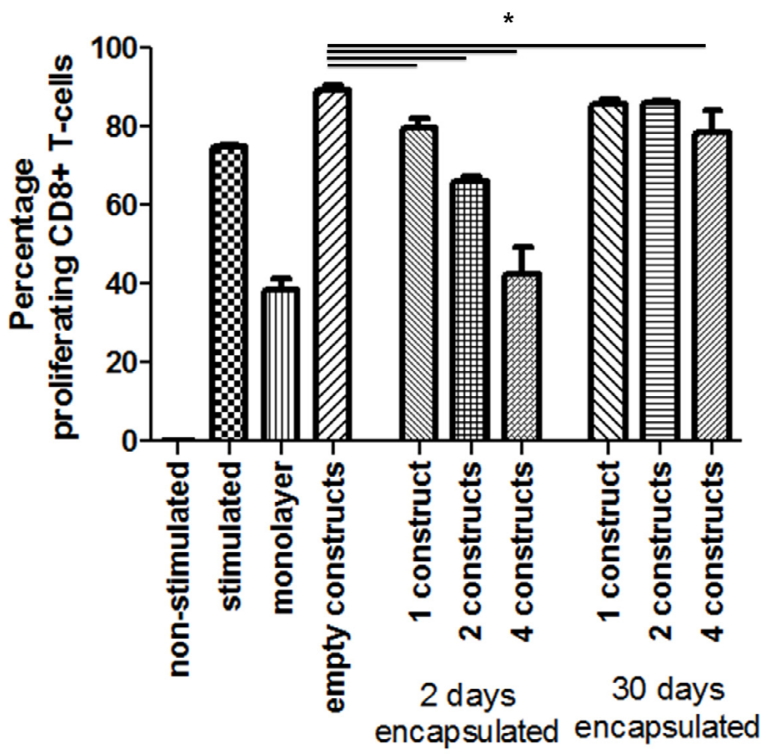

Fig. 5. Inhibition of T lymphocyte proliferation by alginate encapsulated MSCs (approximately $3 \times 10^{4}$ cells/construct). Examples of FACS histograms show the fluorescence intensity of (A) non-stimulated CD4+ T lymphocytes stained with CFSE; (B) anti-CD3/anti-CD28 stimulated CD4+ T lymphocytes stained with CFSE in the presence of empty alginate constructs and $(\mathbf{C})$ anti-CD3/anti-CD28 stimulated CD4+ T lymphocytes co-cultured with 4 MSC-alginate constructs. FACS histograms of stimulated (D) CD4+ T lymphocytes and (D) CD8+ T lymphocytes co-cultured with one, two and four constructs $2 \mathrm{~d}$ and $30 \mathrm{~d}$ after encapsulation of MSCs. Mean $\pm \mathrm{SD}$ is shown. Fluorescence-activated cell sorting, FACS; carboxyfluorescein succinimidyl ester, CFSE. Negative control T lymphocyte proliferation, non-stimulated; positive controls T lymphocyte proliferation, stimulated; proliferation inhibition control, monolayer (approximately $1.2 \times 10^{5}$ cells per well, same cell count as 4 constructs); empty constructs, control (stimulated T lymphocytes co-cultured with 4 empty alginate constructs). * indicates statistical significance.

Long-term retention of MSC properties in alginate

To evaluate their multi-lineage differentiation capacity after encapsulation in alginate, MSCs were released after 2 and $30 \mathrm{~d}$ of encapsulation. Adipogenic and osteogenic differentiation assays were performed and compared with MSCs that were not encapsulated in alginate. The released MSCs could still differentiate adipogenically and osteogenically, although these differentiation capacities were diminished by encapsulation in alginate (Fig. 6 A-F).

Since we observed a decrease in absolute levels of secreted factors and in the inhibition of lymphocyte proliferation after $30 \mathrm{~d}$ in alginate, we evaluated the effect of the alginate encapsulation on MSCs survival by measurements of DNA content of the alginate constructs after $0,7,14,21$ and $30 \mathrm{~d}$ of culture. DNA content diminished after culture of encapsulated MSCs in alginate $(p<0.001)$, reducing viable MSCs numbers by approximately $50 \%$ after $30 \mathrm{~d}$ (Fig. 6G).

\section{Discussion}

MSCs are known to have both trophic and immunomodulatory properties, which can be used for therapeutic applications in regenerative medicine. The possibility of using allogeneic cells would reduce costs and make it more feasible to guarantee certain qualities of the used product, thus increasing the clinical applicability. 


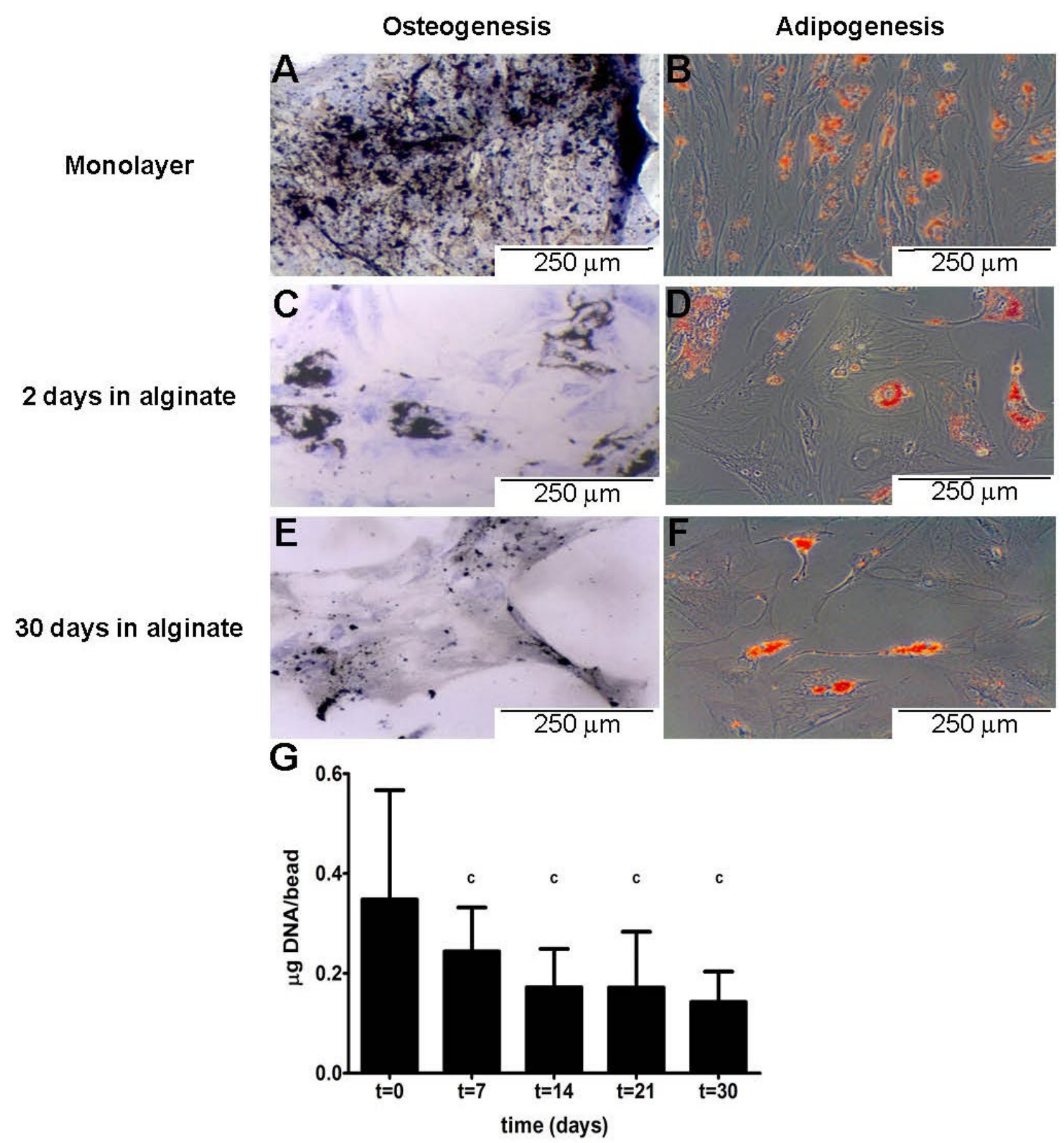

Fig. 6. Osteogenic and adipogenic differentiation of MSCs after encapsulation. Representative pictures are shown. (A,C,E) Von Kossa staining was used for osteogenic differentiation with black indicating calcium-phosphate crystals. $(\mathbf{B}, \mathbf{D}, \mathbf{F})$ Oil Red O staining was used for adipogenic differentiation with red indicating lipid drops. (G) Cell survival over time in vitro of encapsulated MSCs is measured by DNA content of the beads. Mean $\pm \mathrm{SD}$ is shown. ${ }^{\mathrm{a}} p<0.05$, ${ }^{\mathrm{b}} p<0.01,{ }^{\mathrm{c}} p<0.001$ compared to DNA content at $t=0$.

For a potent effect, in particular in chronic inflammatory diseases, cells should remain present locally over a certain period of time. Previous studies using stem cell tracking methods could not demonstrate the long-term presence of these cells after administration in various applications (Ankrum et al., 2014; Fischer et al., 2009; Gholamrezanezhad et al., 2011; Harting et al., 2009). We demonstrated that by encapsulation in alginate, active allogeneic and xenogeneic MSCs were retained over a period of 5 weeks at the implanted location in immunocompetent animals. Moreover, MSC-alginate constructs expressed multiple immunomodulatory properties and trophic properties in vitro.

Protection of allogeneic cells against the host immune system is important since we aim to use allogeneic MSCs to create an "off-the-shelf" therapy. Despite the belief that MSCs are immune evasive or privileged (Ankrum et al., 2014), MSCs viability is reduced when used in inflammatory and immunocompetent environments. Furthermore, it is known that cultured MSCs or MSCs exposed to inflammatory environments can express major histocompatibility complex (MHC)-I and MHC-II. To 
protect allogeneic cells from fast rejection by the immune system of the immunocompetent animals, we encapsulated them in alginate. Alginate has been used before to protect cells against the host immune system (Herrero et al., 2007; Kang et al., 2014; Zanotti et al., 2013). Although in our in vitro assay, alginate appeared to stimulate the proliferation of stimulated T cells, when MSCs were encapsulated, the alginate constructs inhibited $\mathrm{T}$ cell proliferation. After in vivo implantation in an immunocompetent animal, encapsulated allogeneic MSCs were detectable with BLI for up to 5 weeks, indicating local presence and stable viability of the cells. Since no BLI signal of the injected SPIO-Fluc-MSCs was detected from 2 weeks onward, while the hypo-intense SPIO signal remained visible on MRI, we hypothesise that our labelled allogeneic cells died and the SPIO was taken up by macrophages. Histology showed double stained cells for CD68 and Perl's iron staining, thus endorsing this hypothesis. Similarly, the fact that the BLI signal of encapsulated cells remained present throughout the study implies that alginate inhibited cell death and migration.

Human MSC-alginate constructs expressed immunomodulatory and trophic properties in vitro, even after a culture period of $30 \mathrm{~d}$. Although donor variation was found, each donor consistently showed upregulation of gene expression and secretion of these factors after stimulation of the MSCs with inflammatory cytokines. The variation between different MSCs cultures could be due to differences between donors or between isolated subpopulations or as a result of differences introduced during the culture process to expand the cells. MSCs were isolated from patients undergoing total hip replacement surgery by plating out bone marrow on plastic and washing away non-adherent cells after $24 \mathrm{~h}$. This isolation protocol is extensively used in our laboratory, leading to cell populations with multiple MCS characteristics (Farrell et al., 2009; Hellingman et al., 2010), but still to a heterogeneous population. These effects will be less relevant for application if we can use allogeneic cells. In this case, the MSC-alginate constructs can be extensively tested before application in patients and the most effective MSCs will be selected. For the purpose of selection it would be beneficial to know the effectors of the MSC-alginate constructs. For this study we chose to measure IDO, IL-6, TIMPs, TGF- $\beta 1$ and VEGF as factors secreted by MSCs, since these factors are known to play a role in modulating inflammation and tissue repair. IDO in MSCs promotes immunosuppression (Gerdoni et al., 2007; Matysiak et al., 2008; Ryan et al., 2005). IL-6 has been reported to have anti-inflammatory characteristics (Djouad et al., 2007; Xing et al., 1998), as well as pro-inflammatory characteristics (Alonzi et al., 1998; Yamamoto et al., 2000). The maintenance of TIMP-1 and TIMP-2 gene expression we observed may also act locally and control the MMP-induced breakdown of extracellular matrix (Vaalamo et al., 1999). TGF- $\beta 1$ has been associated with immune surveillance and immune suppression mechanisms (Gorelik and Flavell, 2001; Li et al., 2006). Its long-term overexpression leads to severe hyperplasia in normal epidermis or oral mucosa (Li et al., 2004; Liu et al., 2001; Lu et al., 2004). VEGF has been reported to have beneficial effects in certain diseases, such as myocardial infarction, by contributing as a growth factor in the angiogenesis required for tissue repair (Angelo and Kurzrock, 2007; Yuan et al., 2014).

Those molecules are amongst the most frequently reported. However, this is only a small fraction of the biologically active factors that are secreted by MSCs, either soluble or in extracellular vesicles (Bruno et al., 2015; Lavoie and Rosu-Myles, 2013). It is, therefore, important to test the functionality of the secreted factors. $T$ cell proliferation tests are the most commonly used for this purpose. For the MSC-alginate construct used in this study, we found that $2 \mathrm{~d}$ after alginate encapsulation, the inhibition of CD4+ and CD8+ T lymphocyte proliferation was similar to MSCs in monolayer. This indicates that alginate does not prevent the secretion of factors important for inhibition of T cell proliferation. $30 \mathrm{~d}$ after encapsulation in alginate, the MSCs were still able to inhibit T cell proliferation. The effect was reduced, but still statistically significant, which we find encouraging. The data indicate that encapsulated in alginate, MSCs have the potential to inhibit HLA class I (by CD8+) and class II (by CD4+) mediated T cell responses. Our results are in agreement with data showing that MSCs suppress the proliferation of CD4+ and CD8+ T cells in cell contact but also transwell conditions (DelaRosa et al., 2009). The inhibition of CD $8+$ cells can have important implications for the use of MSC encapsulated cells in immune suppression therapy after organ transplantation. It is relevant to mention that pre-stimulation of MSCs with IFN $\gamma / \mathrm{TNF} \alpha$ for $24 \mathrm{~h}$ did not influence the inhibitory effects on T lymphocyte proliferation, which might be explained by the fact that stimulated $\mathrm{T}$ lymphocytes produce IFN $\gamma$ and TNF $\alpha$ that will stimulate the co-cultured MSCs. These findings can have implications for the use of alginate encapsulated MSCs in chronic inflammation. In these conditions factors such as IFN $\gamma$ and TNF $\alpha$ will be present and in particular CD4+ T cells have been demonstrated to play an important role.

For this study we encapsulated MSCs in alginate using a method we have described previously to generate cartilage from long-term culture (Pleumeekers et al., 2014). The MSC-alginate constructs so generated, expressed immunomodulatory capacity. This confirms the recent studies of Stucky and co-workers, demonstrating an inhibition of neuro-inflammation by MSCs that were encapsulated in alginate for $1 \mathrm{~d}$, and Gray and coworkers, demonstrating secretion of factors in reaction to inflammatory cytokines after $2 \mathrm{~d}$ of encapsulation in alginate (Gray et al., 2015; Stucky et al., 2015). We demonstrate, in this study, that MSC encapsulated in alginate can inhibit $\mathrm{T}$ cell proliferation. This capacity, however, was reduced after $30 \mathrm{~d}$ of encapsulation. This can be partly explained by the difference in number of viable cells present at $2 \mathrm{~d}$ and $30 \mathrm{~d}$ after encapsulation. Moreover, we cannot exclude that some of cells have changed their phenotype. We confirmed whether the MSCs still had their multilineage differentiation potential after encapsulation. Since our aim was to retain the immunomodulatory capacity of the encapsulated MSCs and ,therefore, cell differentiation in our construct was not preferred, we evaluated extracellular matrix production of the encapsulated MSCs in vivo at the end of the experiments 
by picrosirius red staining. No positive staining for collagen was found in the constructs (data not shown) suggesting that there was no differentiation of encapsulated MSCs in the constructs. Although we did not evaluate the formation of glycosaminoglycans, we consider it very unlikely that these would be retained in the absence of a collagen matrix. Nevertheless, in the long-term small quantities of matrix formed by MSCs could possibly influence the secretion of immunomodulatory factors and could be playing a role in the diminished immunomodulatory effects of our constructs observed after $30 \mathrm{~d}$.

Immediately after encapsulation we typically find around $30 \%$ loss of cells. In this study, $50 \%$ of the primary encapsulated cells remained viable and the cells did not proliferate. Other studies showed higher cell survival after encapsulation (Barminko et al., 2011; Duggal et al., 2009), which might - among other factors - be explained by differences in cell-type used, the amount of serum in culture medium or the type of alginate used. Whereas most studies used $10 \%$ foetal calf serum for culture, the concentration usually used to expand MSCs, we maintained the MSCs in low serum medium ( $2 \%$ ), which we considered more comparable with the clinical situation after implantation, where the availability of nutrients is likely to be restricted. The alginate environment and the specific medium used might have selected a subpopulation of cells able to survive under these conditions. This population however, retained the capacity to secrete factors in response to inflammatory conditions. Different construct adjustments can be made by adjusting the type of alginate, the alginate concentration and the construct size, which will influence the integrity of the construct and thereby the survival of the MSCs. RGD-alginate is known as a good environment for MSC survival but since it will stimulate cell attachment it is less favourable for preventing host-donor interactions in case of allogeneic cells (Duggal et al., 2009; Markusen et al., 2006). Binder and colleagues (Binder et al., 2014) proposed the co-delivery of alginate with Lysophosphatidic acid (LPA) to rescue undifferentiated MSCs from serum deprivation and hypoxia-induced apoptosis and thus to improve the persistence of undifferentiated MSCs in vivo. Although LPA should be used with care, since it is a potent mitogen and may contribute to oncogenesis, this indicates possibilities for further improvement of the function of MSC-alginate constructs.

The beads can easily be applied during surgical procedures. Moreover, it has been suggested that alginate beads can be used safely and effectively to deliver stem cells percutaneously with minimal loss of viability (Abruzzo et al., 2001; Barminko et al., 2011; Duggal et al., 2009). This holds great promise for use in osteoarthritis, tendinopathy, myocardial infarction or acute spinal cord injury, amongst others. The construct might require further optimisation depending on the final application. For application in osteoarthritis, for instance, where the MSCalginate beads should be delivered in the joint, the ability to withstand mechanical forces in the joint is an important pre-requisite that needs attention. Further fine-tuning the viscoelasticity of the beads (alginate concentration, alginate type, crosslinking) and the size of the beads are important material properties to consider in this respect.

\section{Conclusion}

In vivo allogeneic and xenogeneic MSC-alginate constructs remained locally present at the site of implantation, subcutaneously in an immunocompetent rat for at least 5 weeks. After long-term culture, MSC-alginate beads expressed the ability to interactively modulate their microenvironment by IDO activity and secreting several immunomodulatory and trophic factors such as IL-6, TIMP1 , TIMP-2, TGF- $\beta 1$ and VEGF. MSC-alginate constructs are therefore an interesting system for application in various musculoskeletal diseases with an inflammatory component, such as osteoarthritis, tendinopathy or acute spinal cord injury. Future studies are needed to show how long cells remain encapsulated, to optimise the constructs for specific locations of application and to evaluate what the effect will be in diseased conditions.

\section{Acknowledgements}

We would like to thank Nicole Kops, Yanto Ridwan, Sohrab Khatab and Marcella Franquesa for their help and technical assistance. The authors also gratefully acknowledge the scholarship travel grant to E. Villafuertes conceded by the Osteoarthritis Research Society International (OARSI). Furthermore, the authors gratefully acknowledge the financial support of the NIRM (Netherlands Institute of Regenerative Medicine) and the financial support of the technical foundation STW (project number 12898).

\section{References}

Abruzzo T, Cloft HJ, Shengelaia GG, Waldrop SM, Kallmes DF, Dion JE, Constantinidis I, Sambanis A (2001) In vitro effects of transcatheter injection on structure, cell viability, and cell metabolism in fibroblast-impregnated alginate microspheres. Radiology 220: 428-435.

Alonzi T, Fattori E, Lazzaro D, Costa P, Probert L, Kollias G, De Benedetti F, Poli V, Ciliberto G (1998) Interleukin 6 is required for the development of collageninduced arthritis. J Exp Med 187: 461-468.

Angelo LS, Kurzrock R (2007) Vascular endothelial growth factor and its relationship to inflammatory mediators. Clin Cancer Res 13: 2825-2830.

Ankrum JA, Ong JF, Karp JM (2014) Mesenchymal stem cells: immune evasive, not immune privileged. Nat Biotechnol 32: 252-260.

Awad HA, Wickham MQ, Leddy HA, Gimble JM, Guilak F (2004) Chondrogenic differentiation of adiposederived adult stem cells in agarose, alginate, and gelatin scaffolds. Biomaterials 25: 3211-3222.

Barminko J, Kim JH, Otsuka S, Gray A, Schloss R, Grumet M, Yarmush ML (2011) Encapsulated mesenchymal stromal cells for in vivo transplantation. Biotechnol Bioeng 108: 2747-2758.

Bartholomew A, Sturgeon C, Siatskas M, Ferrer K, McIntosh K, Patil S, Hardy W, Devine S, Ucker D, Deans R, Moseley A, Hoffman R. (2002) Mesenchymal stem cells 
suppress lymphocyte proliferation in vitro and prolong skin graft survival in vivo. Exp Hematol 30: 42-48.

Binder BY, Genetos DC, Leach JK (2014) Lysophosphatidic acid protects human mesenchymal stromal cells from differentiation-dependent vulnerability to apoptosis. Tissue Eng Part A 20: 1156-1164.

Birgersdotter A, Sandberg R, Ernberg I (2005) Gene expression perturbation in vitro a growing case for threedimensional (3D) culture systems. Semin Cancer Biol 15: 405-412.

Bruno S, Deregibus MC, Camussi G (2015) The secretome of mesenchymal stromal cells: role of extracellular vesicles in immunomodulation. Immunol Lett 168: 154-158.

Comoli P, Ginevri F, Maccario R, Avanzini MA, Marconi M, Groff A, Cometa A, Cioni M, Porretti L, Barberi W, Frassoni F, Locatelli F (2008) Human mesenchymal stem cells inhibit antibody production induced in vitro by allostimulation. Nephrol Dial Transplant 23: 1196-1202.

Cukierman E, Pankov R, Yamada KM (2002) Cell interactions with three-dimensional matrices. Curr Opin Cell Biol 14: 633-639.

Daghestani HN, Pieper CF, Kraus VB (2014) Soluble macrophage biomarkers indicate inflammatory phenotypes in patients with knee osteoarthritis. Arthritis Rheumatol 67: 956-965.

De Angelis L, Berghella L, Coletta M, Lattanzi L, Zanchi M, Cusella-De Angelis MG, Ponzetto C, Cossu G (1999) Skeletal myogenic progenitors originating from embryonic dorsal aorta coexpress endothelial and myogenic markers and contribute to postnatal muscle growth and regeneration. J Cell Biol 147: 869-878.

de Vos P, Hoogmoed CG, Busscher HJ (2002) Chemistry and biocompatibility of alginate-PLL capsules for immunoprotection of mammalian cells. J Biomed Mater Res 60: 252-259.

DelaRosa O, Lombardo E, Beraza A, Mancheno-Corvo P, Ramirez C, Menta R, Rico L, Camarillo E, Garcia L, Abad JL, Trigueros C, Delgado M, Buscher D (2009) Requirement of IFN-gamma-mediated indoleamine 2,3-dioxygenase expression in the modulation of lymphocyte proliferation by human adipose-derived stem cells. Tissue Eng Part A 15: 2795-2806.

Di Nicola M, Carlo-Stella C, Magni M, Milanesi M, Longoni PD, Matteucci P, Grisanti S, Gianni AM (2002) Human bone marrow stromal cells suppress T-lymphocyte proliferation induced by cellular or nonspecific mitogenic stimuli. Blood 99: 3838-3843.

Djouad F, Charbonnier LM, Bouffi C, Louis-Plence P, Bony C, Apparailly F, Cantos C, Jorgensen C, Noel D (2007) Mesenchymal stem cells inhibit the differentiation of dendritic cells through an interleukin-6-dependent mechanism. Stem Cells 25: 2025-2032.

Dominici M, Le Blanc K, Mueller I, Slaper-Cortenbach I, Marini F, Krause D, Deans R, Keating A, Prockop Dj, Horwitz E (2006) Minimal criteria for defining multipotent mesenchymal stromal cells. The International Society for Cellular Therapy position statement. Cytotherapy 8: 315 317.

Duggal S, Fronsdal KB, Szoke K, Shahdadfar A, Melvik JE, Brinchmann JE (2009) Phenotype and gene expression of human mesenchymal stem cells in alginate scaffolds. Tissue Eng Part A 15: 1763-1773.

Farrell E, van der Jagt OP, Koevoet W, Kops N, van Manen CJ, Hellingman CA, Jahr H, O'Brien FJ, Verhaar JA, Weinans H, van Osch GJ (2009) Chondrogenic priming of human bone marrow stromal cells: a better route to bone repair? Tissue Eng Part C Methods 15: 285-295.

Fischer UM, Harting MT, Jimenez F, Monzon-Posadas WO, Xue H, Savitz SI, Laine GA, Cox CS Jr (2009) Pulmonary passage is a major obstacle for intravenous stem cell delivery: the pulmonary first-pass effect. Stem Cells Dev 18: 683-692.

Gerdoni E, Gallo B, Casazza S, Musio S, Bonanni I, Pedemonte E, Mantegazza R, Frassoni F, Mancardi G, Pedotti R, Uccelli A (2007) Mesenchymal stem cells effectively modulate pathogenic immune response in experimental autoimmune encephalomyelitis. Ann Neurol 61: 219-227.

Gholamrezanezhad A, Mirpour S, Bagheri M, Mohamadnejad M, Alimoghaddam K, Abdolahzadeh L, Saghari M, Malekzadeh R (2011) In vivo tracking of 111Inoxine labeled mesenchymal stem cells following infusion in patients with advanced cirrhosis. Nucl Med Biol 38: 961-967.

Gonzalez-Rey E, Anderson P, Gonzalez MA, Rico L, Buscher D, Delgado M (2009) Human adult stem cells derived from adipose tissue protect against experimental colitis and sepsis. Gut 58: 929-939.

Gorelik L, Flavell RA (2001) Immune-mediated eradication of tumors through the blockade of transforming growth factor-beta signaling in T cells. Nat Med 7: 11181122.

Gray A, Marrero-Berrios I, Ghodbane M, Maguire T, Weinberg J, Manchikalapati D, SchianodiCola J, Schloss RS, Yarmush J (2015) Effect of local anesthetics on human mesenchymal stromal cell secretion. Nano Life 5: 1550001-1550014.

Griffith LG, Swartz MA (2006) Capturing complex $3 \mathrm{D}$ tissue physiology in vitro. Nat Rev Mol Cell Biol 7: 211-224.

Groh ME, Maitra B, Szekely E, Koc ON (2005) Human mesenchymal stem cells require monocyte-mediated activation to suppress alloreactive T cells. Exp Hematol 33: 928-934.

Guenoun J, Ruggiero A, Doeswijk G, Janssens RC, Koning GA, Kotek G, Krestin GP, Bernsen MR (2013) In vivo quantitative assessment of cell viability of gadolinium or iron-labeled cells using MRI and bioluminescence imaging. Contrast Media Mol Imaging 8: 165-174.

Hansen LK, Mooney DJ, Vacanti JP, Ingber DE (1994) Integrin binding and cell spreading on extracellular matrix act at different points in the cell cycle to promote hepatocyte growth. Mol Biol Cell 5: 967-975.

Harting MT, Jimenez F, Xue H, Fischer UM, Baumgartner J, Dash PK, Cox CS (2009) Intravenous mesenchymal stem cell therapy for traumatic brain injury. J Neurosurg 110: 1189-1197.

Hellingman CA, Koevoet W, Kops N, Farrell E, Jahr H, Liu W, Baatenburg de Jong RJ, Frenz DA, van Osch GJ (2010) Fibroblast growth factor receptors in in vitro and in vivo chondrogenesis: relating tissue engineering using 
adult mesenchymal stem cells to embryonic development. Tissue Eng Part A 16: 545-556.

Herrero EP, Del Valle EM, Galan MA (2007) Immobilisation of mesenchymal stem cells and monocytes in biocompatible microcapsules to cell therapy. Biotechnol Prog 23: 940-945.

Jiang XX, Zhang Y, Liu B, Zhang SX, Wu Y, Yu XD, Mao N (2005) Human mesenchymal stem cells inhibit differentiation and function of monocyte-derived dendritic cells. Blood 105: 4120-4126.

Kang JW, Kang KS, Koo HC, Park JR, Choi EW, Park YH (2008) Soluble factors-mediated immunomodulatory effects of canine adipose tissue-derived mesenchymal stem cells. Stem Cells Dev 17: 681-693.

Kang KS, Lee SI, Hong JM, Park JR, Choi EW, Park YH (2014) Hybrid scaffold composed of hydrogel/3Dframework and its application as a dopamine delivery system. J Control Release 175: 10-16.

Komatsu N, Takayanagi H (2015) Arthritogenic T cells in autoimmune arthritis. Int J Biochem Cell Biol 58: 92-96.

Krampera M, Glennie S, Dyson J, Scott D, Laylor R, Simpson E, Dazzi F (2003) Bone marrow mesenchymal stem cells inhibit the response of naive and memory antigen-specific $\mathrm{T}$ cells to their cognate peptide. Blood 101: 3722-3729.

Kunter U, Rong S, Djuric Z, Boor P, Muller-Newen G, Yu D, Floege J (2006) Transplanted mesenchymal stem cells accelerate glomerular healing in experimental glomerulonephritis. J Am Soc Nephrol 17: 2202-2212.

Lavoie JR, Rosu-Myles M (2013) Uncovering the secretes of mesenchymal stem cells. Biochimie 95: 22122221.

Le Blanc K, Rasmusson I, Sundberg B, Götherström C, Hassan M, Uzunel M, Ringdén O (2004) Treatment of severe acute graft-versus-host disease with third party haploidentical mesenchymal stem cells. Lancet 363: 14391441.

Le Blanc K, Tammik L, Sundberg B, Haynesworth SE, Ringden O (2003) Mesenchymal stem cells inhibit and stimulate mixed lymphocyte cultures and mitogenic responses independently of the major histocompatibility complex. Scand J Immunol 57: 11-20.

Lee OK, Kuo TK, Chen WM, Lee KD, Hsieh SL, Chen $\mathrm{TH}$ (2004) Isolation of multipotent mesenchymal stem cells from umbilical cord blood. Blood 103: 1669-1675.

Lee RH, Seo MJ, Reger RL, Spees JL, Pulin AA, Olson SD, Prockop DJ (2006) Multipotent stromal cells from human marrow home to and promote repair of pancreatic islets and renal glomeruli in diabetic NOD/scid mice. Proc Natl Acad Sci U S A 103: 17438-17443.

Li AG, Wang D, Feng XH, Wang XJ (2004) Latent TGFbeta1 overexpression in keratinocytes results in a severe psoriasis-like skin disorder. EMBO J 23: 1770-1781.

Li MO, Wan YY, Sanjabi S, Robertson AK, Flavell RA (2006) Transforming growth factor-beta regulation of immune responses. Annu Rev Immunol 24: 99-146.

Liu X, Alexander V, Vijayachandra K, Bhogte E, Diamond I, Glick A (2001) Conditional epidermal expression of TGFbeta 1 blocks neonatal lethality but causes a reversible hyperplasia and alopecia. Proc Natl Acad Sci U S A 98: 9139-9144.
Lu SL, Reh D, Li AG, Woods J, Corless CL, Kulesz-Martin M, Wang XJ (2004) Overexpression of transforming growth factor beta1 in head and neck epithelia results in inflammation, angiogenesis, and epithelial hyperproliferation. Cancer Res 64: 4405-4410.

Mallat Z, Tedgui A (2002) The role of transforming growth factor beta in atherosclerosis: novel insights and future perspectives. Curr Opin Lipidol 13: 523-529.

Markusen JF, Mason C, Hull DA, Town MA, Tabor AB, Clements M, Boshoff CH, Dunnill P. (2006) Behavior of adult human mesenchymal stem cells entrapped in alginateGRGDY beads. Tissue Eng 12: 821-830.

Matysiak M, Stasiolek M, Orlowski W, Jurewicz A, Janczar S, Raine CS, Selmaj K (2008) Stem cells ameliorate EAE via an indoleamine 2,3-dioxygenase (IDO) mechanism. J Neuroimmunol 193: 12-23.

Meisel R, Zibert A, Laryea M, Gobel U, Daubener W, Dilloo D (2004) Human bone marrow stromal cells inhibit allogeneic T-cell responses by indoleamine 2,3-dioxygenase-mediated tryptophan degradation. Blood 103: 4619-4621.

Minguell JJ, Erices A (2006) Mesenchymal stem cells and the treatment of cardiac disease. Exp Biol Med (Maywood) 231: 39-49.

Murua R, Portero A, Orive G, Hernandez RM, de Castro M, Pedraz JL (2008) Cell microencapsulation technology: towards clinical application. J Control Release 132: 76-83.

Nauta AJ, Kruisselbrink AB, Lurvink E, Willemze R, Fibbe WE (2006) Mesenchymal stem cells inhibit generation and function of both CD34+-derived and monocyte-derived dendritic cells. J Immunol 177: 20802087.

Ortiz LA, Dutreil M, Fattman C, Pandey AC, Torres G, Go K, Phinney DG (2007) Interleukin 1 receptor antagonist mediates the antiinflammatory and antifibrotic effect of mesenchymal stem cells during lung injury. Proc Natl Acad Sci U S A 104: 11002-11007.

Parekkadan B, Tilles AW, Yarmush ML (2008) Bone marrow-derived mesenchymal stem cells ameliorate autoimmune enteropathy independently of regulatory $\mathrm{T}$ cells. Stem Cells 26: 1913-1919.

Pleumeekers MM, Nimeskern L, Koevoet WL, Kops N, Poublon RM, Stok KS, van Osch GJ (2014) The in vitro and in vivo capacity of culture-expanded human cells from several sources encapsulated in alginate to form cartilage. Eur Cell Mater 27: 264-280.

Popp FC, Eggenhofer E, Renner P, Slowik P, Lang SA, Kaspar H, Geissler EK, Piso P, Schlitt HJ, Dahlke MH (2008) Mesenchymal stem cells can induce long-term acceptance of solid organ allografts in synergy with lowdose mycophenolate. Transpl Immunol 20: 55-60.

Ren G, Zhang L, Zhao X, Xu G, Zhang Y, Roberts AI, Zhao RC, Shi Y. (2008) Mesenchymal stem cell-mediated immunosuppression occurs via concerted action of chemokines and nitric oxide. Cell Stem Cell 2: 141-150.

Rodriguez-Merchan EC (2014) Intra-articular injections of mesenchymal stem cells for knee osteoarthritis. Am J Orthop (Belle Mead NJ) 43: E282-291.

Royce PM, Lowther DA (1979) Fluorimetric determination of DNA in papain digests of cartilage, using ethidium bromide. Connect Tissue Res, 6: 215-221. 
Ryan JM, Barry FP, Murphy JM, Mahon BP (2005) Mesenchymal stem cells avoid allogeneic rejection. J Inflamm (Lond) 2: 8.

Schmittgen TD, Livak KJ (2008) Analysing real-time PCR data by the comparative C(T) method. Nat Protoc 3: 1101-1108.

Shoichet MS, Rein DH (1996) In vivo biostability of a polymeric hollow fibre membrane for cell encapsulation. Biomaterials 17: 285-290.

Sottile V, Halleux C, Bassilana F, Keller H, Seuwen K (2002) Stem cell characteristics of human trabecular bone-derived cells. Bone 30: 699-704.

Stucky EC, Schloss RS, Yarmush ML, Shreiber DI (2015) Alginate micro-encapsulation of mesenchymal stromal cells enhances modulation of the neuroinflammatory response. Cytotherapy 17: 1353-1364.

Toma C, Pittenger MF, Cahill KS, Byrne BJ, Kessler PD (2002) Human mesenchymal stem cells differentiate to a cardiomyocyte phenotype in the adult murine heart. Circulation 105: 93-98.

Trouche E, Girod Fullana S, Mias C, Ceccaldi C, Tortosa F, Seguelas MH, Calise D, Parini A, Cussac D, Sallerin B (2010) Evaluation of alginate microspheres for mesenchymal stem cell engraftment on solid organ. Cell Transplant 19: 1623-1633.

Vaalamo M, Leivo T, Saarialho-Kere U (1999) Differential expression of tissue inhibitors of metalloproteinases (TIMP-1, $-2,-3$, and -4) in normal and aberrant wound healing. Hum Pathol 30: 795-802.

van Buul GM, Kotek G, Wielopolski PA, Farrell E, Bos PK, Weinans H, Grohnert AU, Jahr H, Verhaar JA, Krestin GP, van Osch GJ, Bernsen MR (2011) Clinically translatable cell tracking and quantification by MRI in cartilage repair using superparamagnetic iron oxides. PLoS One 6: e17001.

Wang XJ, Dong Z, Zhong XH, Shi RZ, Huang SH, Lou Y, Li QP (2008) Transforming growth factor-beta1 enhanced vascular endothelial growth factor synthesis in mesenchymal stem cells. Biochem Biophys Res Commun 365: 548-554.

Wong M, Siegrist M, Wang X, Hunziker E (2001) Development of mechanically stable alginate/chondrocyte constructs: effects of guluronic acid content and matrix synthesis. J Orthop Res 19: 493-499.

Wu TJ, Huang HH, Hsu YM, Lyu SR, Wang YJ (2007) A novel method of encapsulating and cultivating adherent mammalian cells within collagen microcarriers. Biotechnol Bioeng 98: 578-585.

Xing Z, Gauldie J, Cox G, Baumann H, Jordana M, Lei XF, Achong MK (1998) IL-6 is an antiinflammatory cytokine required for controlling local or systemic acute inflammatory responses. J Clin Invest 101: 311-320.

Yamada KM, Cukierman E (2007) Modeling tissue morphogenesis and cancer in 3D. Cell 130: 601-610.

Yamamoto M, Yoshisaki K, Kishimoto T, Ito H (2000) IL-6 is required for the development of Th1 cell-mediated murine colitis. J Immunol 164: 4878-4882.
Yuan Q, Sun L, Li JJ, An CH (2014) Elevated VEGF levels contribute to the pathogenesis of osteoarthritis. BMC Musculoskelet Disord 15: 437.

Zanotti L, Sarukhan A, Dander E, Castor M, Cibella J, Soldani C, Trovato AE, Ploia C, Luca G, Calvitti M, Mancuso F, Arato I, Golemac M, Jonjic N, Biondi A, Calafiore R, Locati M, D’Amico G, Viola A (2013) Encapsulated mesenchymal stem cells for in vivo immunomodulation. Leukemia 27: 500-503.

Zhang J, Huang X, Wang H, Liu X, Zhang T, Wang Y, $\mathrm{Hu} \mathrm{D}$ (2015) The challenges and promises of allogeneic mesenchymal stem cells for use as a cell-based therapy. Stem Cell Res Ther 6: 234.

\section{Discussion with Reviewer}

Marphy Murphy: Did the authors check the lungs and spleen for MSCs that were injected systemically?

Authors: The main aim of the in vivo study was to investigate whether encapsulated MSCs remained viable in the same location for a longer time, compared to injected cells. We transplanted and injected the MSCs subcutaneously, rather than injecting the MSCs systemically and during the 5 weeks of follow-up, SPIO was seen with MRI at the locations of injection. With histology, we found double staining for CD68 and Perl's iron staining at the location of the subcutaneous injection. This indicates that the majority of MSCs most likely died and macrophages phagocytised the SPIO. We did not check the lungs and spleen for MSCs. There is a possibility that some MSCs have migrated from the subcutaneous location into the vascular system and thereby infiltrate organs, but this was not our focus in this study.

Marphy Murphy: $24 \mathrm{~h}$ media change following MSCs isolation is quite a short time (normally 3-4 d media change is used for most of in vitro and cell transplantation work) This may have affected experimental outcome compared to using a cell population obtained using the standard 3-4 d plastic adhesion method.

Authors: This isolation method is extensively used in our laboratory and an established method for a long time. The MSCs fraction in bone marrow will adhere within $24 \mathrm{~h}$ to the pre-coated culture plastic. All non-adherent cells such as haematopoietic cells and erythrocytes need to be washed away to get a clear MSCs isolation. This way we grow colonies in the first week that can be used for further cell expansion. These cells are being used for chondrogenic, osteogenic and adipogenic differentiation. We can indeed not exclude that another way of isolating would lead to a different cell population.

Editor's note: The Scientific Editor responsible for this paper was Martin Stoddart. 